\title{
Storing Grains for Food Security and Sustainability
}

\author{
Digvir S. Jayas
}

Received: 2 October 2011 / Accepted: 28 November 2011/Published online: 19 January 2012

(C) NAAS (National Academy of Agricultural Sciences) 2012

\begin{abstract}
Globally over two billion tonnes of grains are produced annually. The grains are stored at different stages of the grain distribution chain, in defined units such as bags, silos, warehouses, containers and even in piles on the ground. An individual unit or a group of units can be managed as man-made ecosystems, where deterioration of the stored grain is a result of interactions among physical, chemical, and biological factors. Accurate estimates of post-harvest losses of grains are not available, but it can vary from $1-2 \%$ in the developed countries, where grain is stored in well managed facilities, to $20-50 \%$ in less developed countries, with poorly managed storage systems. Considerable knowledge has been generated to understand the critical parameters for developing efficient grain storage systems. Through proper monitoring and management of interactions, both biotic and abiotic in nature, stored-grains can be protected for over a long period. There is an urgent need to synthesize the status of knowledge to provide directions for future research and development, to minimize the post-harvest losses of grains in different regions of the world.
\end{abstract}

Globally over two billion tonnes (Gt) of cereals, oilseeds, and pulses (collectively referred to as grains) are produced annually for consumption by humans and domesticated animals to meet the nutritional requirement of humans. The produced grains are stored at different stages of the grain distribution chain between the producer and the consumer. Obvious reasons for storing grain are: place of consumption is different than the place of production, production is seasonal and consumption is year round, place of processing is different than the place of production, grains are kept to deal with emergency needs such as famine, and grains are kept as seed for the next planting.

Accurate estimates of post-harvest losses of grains are not reported by most of the countries in a consistent manner, but the losses can vary from 1 to $2 \%$ in some of the developed countries where grain is stored in wellmanaged facilities with aeration and drying capabilities

D. S. Jayas $(\bowtie)$

Biosystems Engineering, University of Manitoba, Winnipeg, MB R3T 2N2, Canada

e-mail: digvir_jayas@umanitoba.ca
(Fig. 1) to 20-50\% in some of the less developed countries under poorly managed storage systems (Fig. 2), [2-4]. Sometimes, in a single unit of storage (e.g., a bin or warehouse) it is possible that total grain can be spoiled making it unsuitable for human consumption thus resulting in $100 \%$ loss in the unit.

In the countries where grain storage losses are high, the growth in population is also high leading to increase in food demand. In response to the growing food demand, the policy makers and scientists have responded by placing emphasis on increasing food production, and their achievements have been commendable. They have succeeded in doubling and tripling grain production. Unfortunately, very little attention, in some cases none, has been paid to reduce storage losses. In terms of grain availability, which must increase as the world population grows, investments in good grain storage systems would be more rewarding. Let us consider a country that produces say $50 \mathrm{Mt}$ of grains and $50 \%$ is lost, leaving only $25 \mathrm{Mt}$ for consumption. Now, through cultivar development and intensive cultivation practices, let's say this country doubles its production to $100 \mathrm{Mt}$ but still loses half of it, providing only $50 \mathrm{Mt}$ for consumption. Considering the 

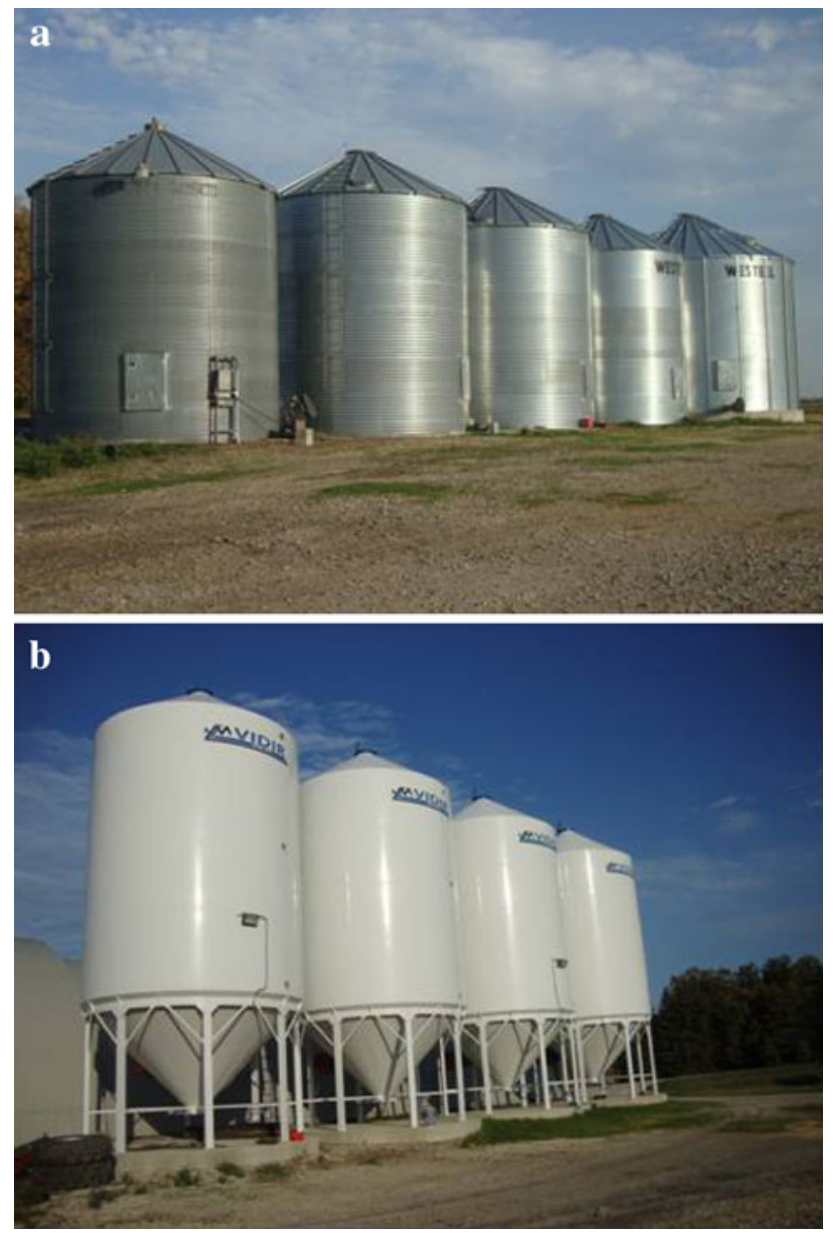

Fig. 1 a An example of good storage system using flat-bottom bins with aeration and drying capabilities. b An example of good storage system using hopper-bottom bins with aeration and drying capabilities

same country, had she spent her resources on preserving the grain produced so that only $2 \%$ of the grain was lost, then, out of the original $50 \mathrm{Mt}$, about $48 \mathrm{Mt}$ would have been available. This approach would necessitate an increase in production of only $2 \mathrm{Mt}$, because a grain saved is equal to a grain produced.

Increases in the production have been possible through increases in the use of inputs and in some parts of the world by an increase in arable land or a combination of both. These approaches have significant negative environmental impacts. Also, these increases have come at a much higher price compared to the cost of development and adoption of preservation methods for grain storage. By using new technologies for preservation, enhancing the understanding of stored-grain ecosystems and developing and adopting loss detection and prevention methods, it is possible to increase grains available for consumption. I hope that the policy makers and scientists will include in their twodimensional plans of population growth and grain production a third dimension, that is, grain storage. By
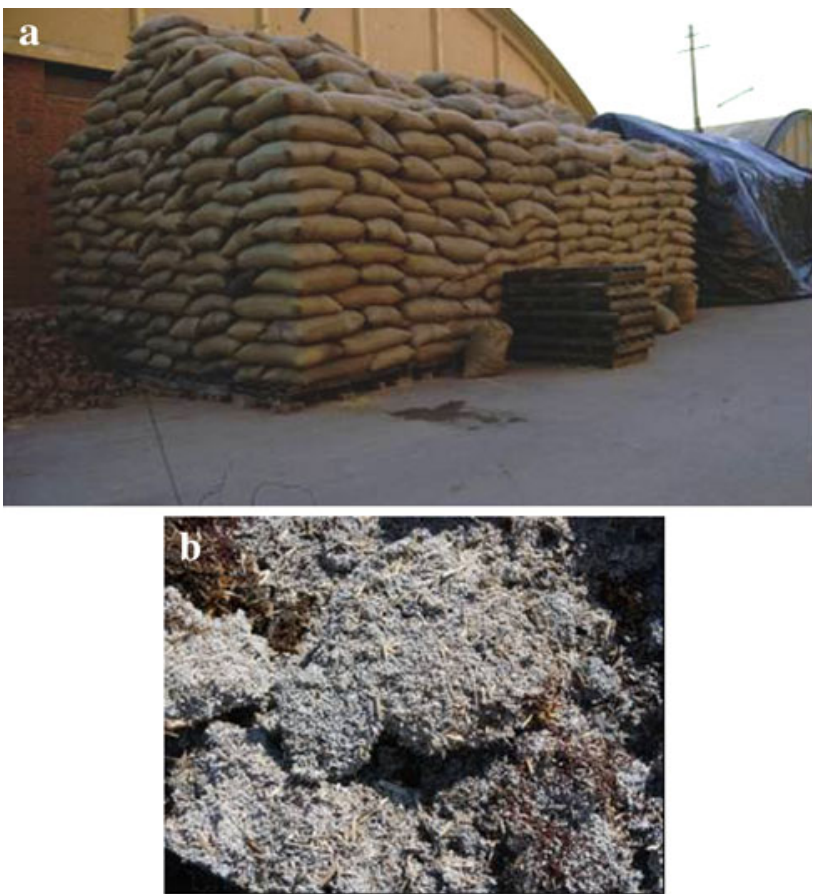

Fig. 2 a An example of unprotected bag storage system. b An example of spoiled canola due to poor storage

enhanced research and development in grain preservation techniques, the potential is there to reduce the use of fertilizers, fuel, and water for per capita availability of grain, to reduce the amount of land under grain production, thus having a positive environmental impact. Similar logic can also be applied to perishable produce that is consumed fresh, like, fruits and vegetables.

Another advantage of proper storage systems is the improved health of humans and animals who consume grains. The grains infected by fungi not only develop offodours but can also lead to contamination by mycotoxins, which can have deleterious health effects for both animals and humans $[1,6,11]$. At times, consumption of mycotoxins could be lethal. Similarly, infestation by insects, rodents and birds can also cause off-odours as well as contamination from feces and other body parts [9, 10]. Improved quality of raw materials will also result in production of high quality food products. No food processing technique can improve on poor quality of raw material.

The governments of countries with high post harvest losses must consider the produced grains as a national asset and should allocate considerable resources to protect them. Currently, the governments in many countries see grains as belonging to farmers and thus loss in quality and quantity of grains is borne by the farmers but, at the same time, national governments typically import grains to meet the demand of their citizens at a considerably higher cost. If grains were treated as a national asset and protected, then 
the demand for imports could be reduced, saving valuable foreign currency. Reducing losses for countries that export grain should generate additional income for the country and its producers resulting in higher standard of living for her citizens. Therefore, a national plan to develop a proper infrastructure over a few years and a proper training program through strong extension services for grain storage managers can significantly increase available grains. For example, a country with $50 \%$ loss can almost double the supply of available grains if stored grain losses were reduced to less than $2 \%$. This is achievable if current scientific knowledge is properly applied and if farmers and storage managers are provided proper advice and training in managing stored grains. The funds spent on protecting produced grains and on training people can be paid back in a very short period, typically two to three years. What is needed is the national will and commitment to make this happen.

Grains are stored in defined units such as bags, silos, warehouses, containers and even in piles on the ground. An individual unit or a group of units can be managed as manmade ecosystems where deterioration of the stored grain is a result of interactions among physical, chemical, and biological factors (Fig. 3). The important factors are: temperature, moisture, carbon dioxide $\left(\mathrm{CO}_{2}\right)$, oxygen $\left(\mathrm{O}_{2}\right)$, grain characteristics, microorganisms, insects, mites, rodents, birds, geographical location, and granary structure. Through proper monitoring and management of interactions, both biotic and abiotic in nature, stored-grain can be protected for over long term. For example, safe storage of grains can be accomplished by manipulating two important physical factors: temperature and moisture content (Fig. 4) provided

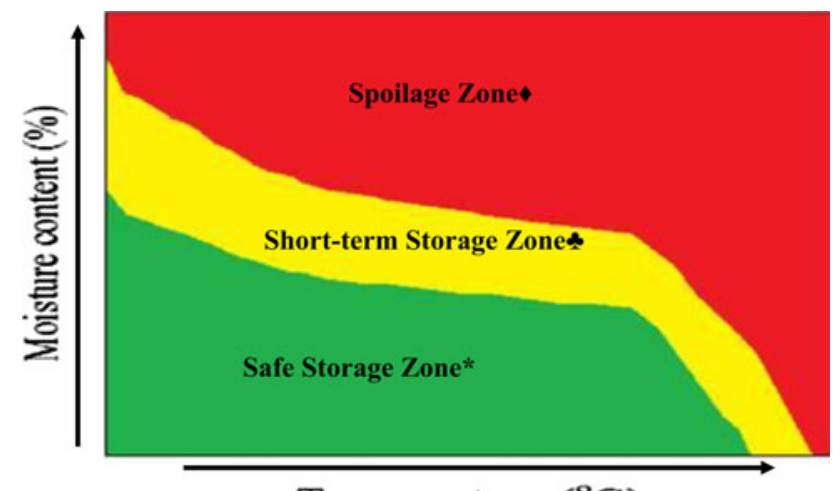

Temperature $\left({ }^{\circ} \mathrm{C}\right)$

Fig. 4 Relationship between temperature and moisture content for safe storage of grains. Asterisk safe storage zone, clover short-term storage zone, filled diamond spoilage zone

the grains are not affected by other external factors such as insects, mites, rodents, or birds. Grains stored at high moisture and high temperatures spoil quickly (Fig. 4). The spoilage may be reflected by the end use of the grain. But a drop in germination, presence of visible mould, increase in free fatty acids or a combination of all the three are commonly used to measure spoilage $[7,8]$. Drop in germination seems to occur first and, therefore, has been considered as the most sensitive parameter. The width of the short-term storage zone and the values for the axes labels for temperature and moisture content in Fig. 4 are dependent on the type of grain and can guide in choosing a proper combination of temperature and moisture content for safe storage. For example, the moisture content for storing wheat safely for up to a year under a temperate climatic conditions is $12-$ $13 \%$ wet basis but, for storing canola (an oilseed crop), it is
Fig. 3 Interactions of a storedgrain ecosystem (modified from [5]). Dragger external factors determined by the geographical location of the storage structure and the type of the structure, asterisk partial differential equation based transfer models, double dragger internal generation terms, open diamond predicted variables, filled diamond biomodels describing insects, mites and fungi population dynamics as a function predicted variables

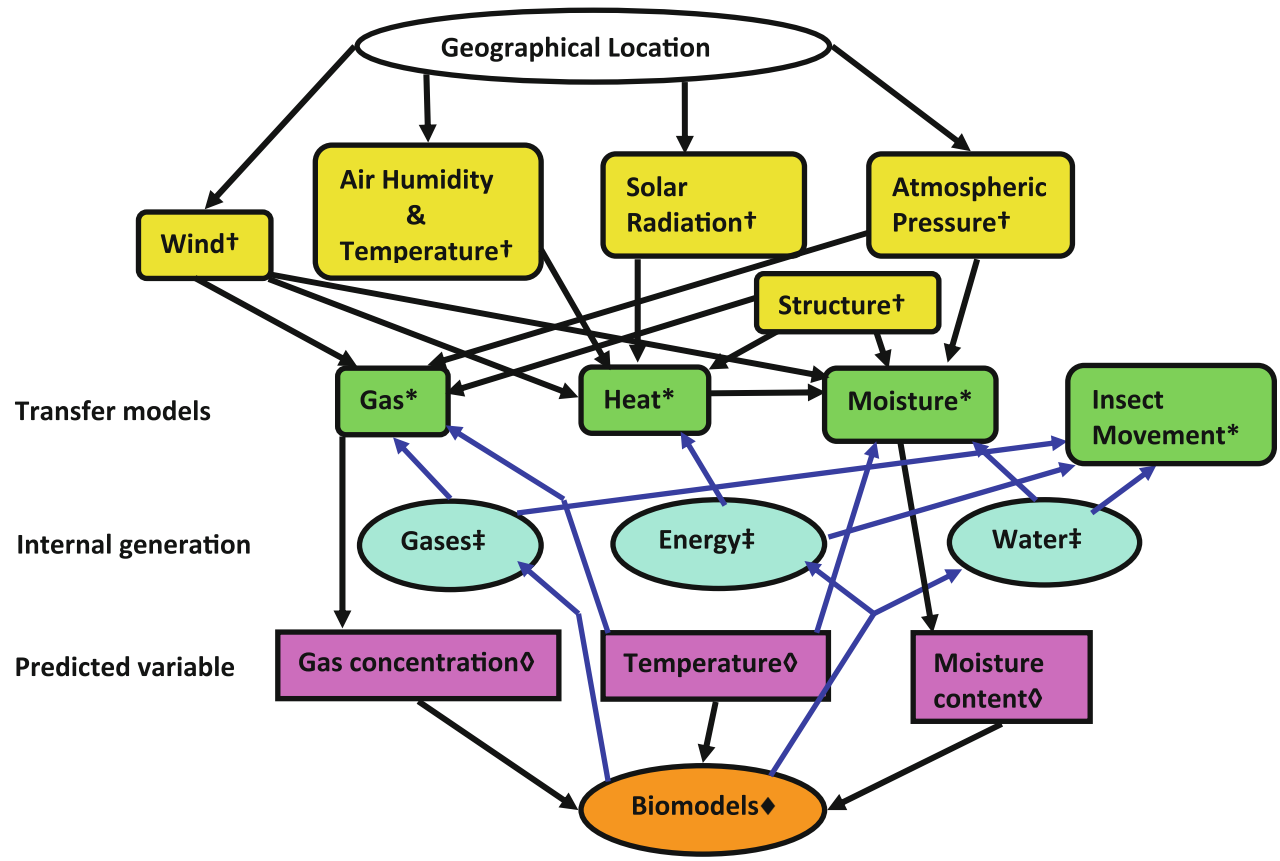


Box 1 Critical parameters for developing efficient grain storage systems

Physical parameters of grains
Grain quality parameters
Near infrared (NIR) and hyper-spectral imaging for grain quality
monitoring
Digital image processing for monitoring grain quality and for
automating grain handling
Sensors for detecting grain spoilage
Grain grading standards
Defining safe storage limits for grains
Interactions in stored-grain ecosystems and the factors leading to
grain spoilage
Detection of insects in grains
Insect population dynamics and movement
Insect control strategies
Fungal infection
Grain spoilage control strategies
Aeration
Near ambient drying
High temperature drying

8-9\%. Similar guidelines are needed for different grains under different climatic zones of the world and should be based on different spoilage characteristics.

Considerable knowledge has been generated to understand various critical parameters for developing efficient grain storage systems (Box 1). There is an urgent need to synthesize the status of knowledge to provide directions for future research and development on these topics for various regions of the world. Along with syntheses of research results or knowledge bank, proper guidelines and training material must be developed and distributed to farmers and storage managers. There is also a need to develop proper training programs on food preservation for extension workers in collaboration with the universities. The universities should also develop region specific educational programs focused on food preservation. In addition, considering that spoilage occurs due to interactions among biotic and abiotic factors, there is a need for multidisciplinary teams of engineers, entomologists, chemists, mycologists, and agricultural economists to work together to develop practical solutions. Depending on the problem to be solved, quantum of input from experts could vary but strong ongoing consultation and communication among team of experts is a must. For example, in the design of grain aeration and drying systems with associated controls, engineers will play a larger role whereas to enhance the understanding of behaviour of insects in that particular region, entomologists will play a larger role.

\section{References}

1. Abramson D, Hulasare R, York RK, White NDG, Jayas DS (2005) Mycotoxins, ergosterol, and odor volatiles in durum wheat during granary storage at $16 \%$ and $20 \%$ moisture content. J Stored Prod Res 41:67-76

2. FAO (2007) Global cereal grains production and post harvest losses. www.faostat.fao.org. Accessed 25 Nov 2011

3. Hill DS (1990) Pests of stored products and their control. CRC Press Inc., Boca Raton

4. Hill DS (2002) Pests of stored foodstuffs and their control. Kluwer Academic Publishers, Norwell

5. Jayas DS (1995) Mathematical modelling of heat, moisture, and gas transfer in stored grain ecosystems. In: Jayas DS, White NDG, Muir WE (eds) Stored grain ecosystems, Marcel Dekker, New York, pp 527-567

6. Magan N, Hope R, Cairns V, Aldred D (2003) Post-harvest fungal ecology: Impact of fungal growth and mycotoxin accumulation in stored grain. Eur J Plant Pathol 109:723-730

7. Pomeranz Y (1992) Biochemical, functional and nutritive changes during storage. In: Anderson JA, Alcock AW (eds) Storage of cereal grains and their products. American Association of Cereal Chemists, St. Paul, pp 55-141

8. Rajarammanna R, Jayas DS, White NDG (2010) Comparison of deterioration of rye under two different storage regimes. J Stored Prod Res 46:87-92

9. Smith RH (1995) Rodents and birds as invaders of stored-grain ecosystems. In: Jayas DS, White NDG, Muir WE (eds) Stored grain ecosystems, Marcel Dekker, New York, pp 289-323

10. White NDG (1995) Insects, mites, and insecticides in stored-grain ecosystems. In: Jayas DS, White NDG, Muir WE (eds) Stored grain ecosystems, Marcel Dekker, New York, pp 123-167

11. Wilson DM, Abramson D (1992) Mycotoxins. In: Sauer DB (ed) Storage of cereal grains and their products. American Association of Cereal Chemists Inc., St. Paul, pp 341-391 